Moritz Emmelmann

\title{
Religion in Soylent Green
}

Based on Harry Harrison's dystopian novel Make Room! Make Room! (1966), Richard Fleischer's Soylent Green (1973) is set in New York in the year 2022. As police officer Robert Thorn and his roommate Solomon (Sol) Roth investigate the assassination of William R. Simonson, an executive of the world's largest food corporation "Soylent," they gradually unveil a much larger criminal plot. Although Thorn fails to retain information from a priest to whom Simonson had confessed shortly before his death, Sol acquires classified information revealing that the widely consumed food surrogate Soylent Green is made from dead people. Sol reacts to this revelation by ending his life in a semi-religious euthanasia facility, while Thorn decides to continue his investigations. He follows a corpse transport, finds proof for his theory and, badly wounded by contract killer Tab Fielding, manages to inform his chief officer of the scandal at the end of the film.

The living conditions in the world of Soylent Green are characterized by massive overpopulation, environmental destruction and extensive crime. The fictional New York of 2022 is chronically underserved with respect to food, housing, sanitation and electricity. Its inhabitants have to face corruption, police brutality and the unrivalled monopoly of the Soylent Corporation that fixes prices and produces food from its deceased customers. These outrageous circumstances are a call to arms for helpers of the "poor and orphaned" (Psalms 10,14). When learning that 
the food substitute Soylent Green is made from the dead, the Christian Church, with the priest as its representative, becomes involved in the film's central conflict. This dramatic situation provides a test case for the church's charitable and moral ambitions. The conduct within the ambit of the church, which extends to the church building and its members, differs starkly from the procedures in the outside world, which is controlled by the government and the Soylent Corporation. In fact, it creates the impression of a religious sphere with an inside that acts as a sanctuary opposing the moral decay in the society shown in the film. By these means, the film draws attention towards the depiction of religion and especially of the Christian Church.

Few works have been published on Robert Fleischer's 1973 film Soylent Green and none of them have discussed the topic of religion in great detail. When the film receives scholarly attention - usually in the context of more encompassing studies on science fiction film - religion is typically featured as one component among many. Furthermore, analyses of Soylent Green vary considerably: They provide a number of conclusive readings, yet generally neglect to consider the film as a piece of art in its own right. In Screening Space: The American Science Fiction Film, Vivian Sobchack, for example, has provided a short discussion of the filmic devices in Soylent Green in which she focuses solely on how the dystopian film communicates the people's alienation from nature and their dehumanization (131-32). The film's final revelation that "Soylent Green ... is ... PEOPLE!," on the other hand, serves as the title and guiding metaphor of Ronnie D. Lipschutz's article on "Labour, Bodies and Capital in the Global Political Economy." In his assessment of our present-day economy, Lipschutz links fact and fiction by arguing that the horrible cycle Soylent Green envisions for future food production and consumption can already be detected on today's labor markets where the laboring body is constantly consumed and recreated (573-76). Finally, Pat Bereton briefly reviews the film as one example of her larger survey on the theme of ecology in the American cinema, and points out an exceptional explicitness of both the film's environmental dystopia and a utopian alternative of pastoral harmony. She aptly calls the latter a vision of "(post)secular spiritualism" and mentions in a footnote that main actor Charlton Heston appeared repeatedly in stories of biblical or spiritual content (169-70). The widespread neglect of instances of religion, then, is all the more surprising as religious elements, characters and institutions occupy central positions in the film and together provide much material for interpretation. Numerous interrelations created through means of plot development, symbolism and contrast form a thoroughly crafted discourse that deserves consideration in the evaluation of the film.

In this chapter, I will show that in the context of an extreme social, economic and moral crisis, Soylent Green presents the Christian Church as a charitable institution offering both spiritual leadership and moral integrity. Regardless of its limited factual capacities, hope for positive change centers on the efforts and services of 
the church. Certainly, my background as a student of theology helped me to develop interest in this specific aspect. Nevertheless, this chapter is not meant as a theological review of the film, but as a film analysis that focuses on the religious elements in Soylent Green. ${ }^{1}$

\section{Instances of Religion}

The fictional world of Soylent Green is not dominated by religion, not ruled by religious leaders and not characterized by spirituality. And yet, a number of peculiar incidents, comments and character relationships draw attention to its religious dimension, adding a number of subtle yet dramatic linkages between the morally corroded reality of Soylent Green and religious practices and traditions. The religions featured in the film are Judaism and the Roman Catholic denomination of Christianity. Even though the society portrayed appears to be very multicultural, there are no instances of other world religions. However, we do find an important third party to the spiritual world of Soylent Green: a fictional, semi-religious death cult that is located around euthanasia facilities maintained by the ever-present Soylent Corporation. This cult incorporates certain elements of both Judaism and Christianity within a heathenish ritual, but it never abandons its central theme and purpose of assisting in suicide.

I will now turn to a more detailed analysis of those instances in the film in which religions play a role. With this, I seek firstly to gain access to the religious discourse in the film and secondly to evaluate the religions' respective functions.

\section{Judaism}

The representative of Judaism in Soylent Green is the old man Solomon Roth. His affiliation to the Jewish religion first becomes clear shortly before the dinner scene, when he says the Hebrew toast "Le Chaim" before drinking the whiskey that his friend Robert Thorn has brought home. Also, his first name is not an unusual one for a man with Jewish ancestors. In the biblical tradition, Solomon is the name of one of the great kings of Israel. His regency is said to have been a time of peace and prosperity as well as political stability. Under his successor, the unity of the twelve tribes was lost and the faith in Jahveh deteriorated (2 Chronicles 9 18-27; 12). Solomon Roth makes no specific comments about his religious beliefs and does not appear to practice his religion in terms of prayer, service attendance or study of the scripture. He frequently makes exclamations like "Oh God"

\footnotetext{
This paper was written in the context of a seminar titled "Of Body Snatchers and Cyberpunks" at the University of Göttingen in the summer term of 2009, held by Kathleen Loock. Its content, structure and mode of argumentation have been both developed and criticized throughout the course and therefore owe credit to the participants of the course and the teaching staff.
} 
and at one point tells Thorn to "go with God," which seems to be a habit or a tradition rather than a calling upon God or a blessing. In this context, it is very remarkable how he comes to undergo the death ritual of the euthanasia cult. As he once more exclaims "Oh God" upon the shocking discovery that Soylent Green is made from the dead, the head of the information exchange takes him by his word and eerily poses the question: "What God, Mr. Roth? Where will we find him?" In the face of his devastating knowledge, this question becomes relevant to Solomon and he answers: "Perhaps at home. Yes, at home." The expression "at home" refers to voluntary execution in a euthanasia facility and indicates that Roth is able to project his personal spirituality onto the ritual of the euthanasia cult, although the latter does not relate itself to the Jewish God in any way. Rather the cult serves as the projection surface for individual religious longings. This becomes clear in the scene following Roth's resolution to go home, in which we see him walking through a dark and empty street towards the brightly illuminated euthanasia facility. Its basic features of light, warmth and cleanliness as well as the video show of nature scenes, impressive lighting and music during the dying ceremony allow people to have a spiritual experience regardless of their actual religious background. In Solomon's case this apparently bridges the discrepancy between the ritual and the Jewish law forbidding murder and suicide.

As Roth is the only representative of the Jewish religion in the film, it is licit to draw conclusions from his attitude towards Judaism about the film's portrayal of it in general. The religion's chief function here is to serve as a hoard of tradition and as a connector to a better past. Therefore, the film does not portray Jewish practices or sacred buildings, but instead associates it with books, knowledge and narration. For example, Solomon himself is referred to as "the book" because of his job as police assistant and the center of his professional life is the "exchange" that resides in the public library. Roth's first name relates to a grand past and so do the stories he tells Thorn of a better time before the age of Soylent. In a very literal sense, Judaism is portrayed in the film as a religion of the book, which corresponds with its focus on religious documents and the command to pass on knowledge as given in the Jewish creed "Shema Yisrael" (Deuteronomy 6, 4-9).

\section{Christianity}

In Soylent Green, instances of Christianity are present in the form of utterances, characters, rituals and specific localities. Such connections are remarkably numerous and call for a serious consideration of the religion's role and function in the film.

The church building is one example of the church's involvement in the conflict over secrecy or publication of the fact that Soylent Green is made from corpses. It is host to a number of scenes including parts of the investigation and the final battle between hero Robert Thorn and his antagonist Tab Fielding. This 
repeated use of the building as a setting may be read to indicate an understanding of the church as a relevant factor in moral issues. The church's counterpart is a euthanasia facility, which forms the religious center of the euthanasia cult and therefore may also be described as a temple. However, their purposes are altogether different: The church provides housing and some medical care - the facility is the site of mass homicide. It is also noteworthy that the film shows no Jewish synagogue and gives no explanation for this gap. In my opinion, speculations on this topic have no basis in fact and run the risk of inappropriately transferring historic events to a work of fiction.

Another instance of Christianity is the church personnel, represented by an African American priest named Paul. The very engagé clergyman heads the church's charitable activities and becomes intertwined with Thorn's investigation when the Soylent Green manager William Simonson confesses that his company's products are not harvested from the ocean as the public is told, but in truth are made from the dead. With the priest gaining the same knowledge as Simonson - and later on Solomon and Thorn - the church joins the small group of people who know the secret of Soylent Green. Because of this entanglement via its very own practice of confession, the church is forced to react. Upon learning about the production of Soylent food, the church neither takes the initiative like Thorn, nor is it forced into resignation like Solomon. The church's resolution is to continue its service to the poor and sick, although it is questionable whether the priest will be able to fulfill his duties effectively in the future. This reaction is bound to be compared with that of other characters as the viewer's attention turns towards the moral assessment of different ways of dealing with the most appalling truth: that, in the words of Robert Thorn, "Soylent Green is people."

Christian rites and traditions are also present with some of the minor characters, hinting at some awareness of a Christian heritage in the society of Soylent Green. Simonson, apprehending his near assassination, confesses to the priest. Simonson's former concubine later expresses her regret at the lack of a traditional funeral for him, which indicates that she is still familiar with the religious dimension death used to have in former times. Furthermore, the homeless masses sheltered within the church make frequent use of the offer of confession. This sign of religious earnestness is probably caused by the danger of death that is present throughout the film and might occur at any time due to disease, malnutrition or the violent environment. These examples show a strong association of the church with rites and ceremonial actions as well as a general understanding of the church as something not quite obsolete but rather traditional. At the same time, the use of the church building as setting for important scenes denotes its significance for the events. 


\section{Euthanasia Cult}

A third religious element in the film is a death cult involving the euthanasia of people seeking to escape life in the world of Soylent Green. In a ceremony reminiscent of heathenish rituals, these people are placed on a stretcher, given a toxic drink and then granted a video show of nature scenes accompanied by music and special lighting. This procedure results in the death of the person, after which the corpse is quickly removed from the ceremonial room and then brought to factory grounds to be processed into Soylent Green.

On a spiritual level, this cult centers around the notion of "going home," meaning the act of voluntary execution. While there is no further theological or esoteric foundation to this idea in the film, the existence of a place called "home" seems to be a common thought. No certain destination or spiritual goal is announced in order to promote "going home." The devastating living conditions evidently are enough to create escapist longings in vast parts of the general public. Strikingly, the conditions of the procedure - no pain, a twenty-minute video show with shots of nature scenes and a choice of music - are widely known and hardly need to be mentioned again in the facility itself. Because no applicant for "going home" lives to tell others about the ritual, it can be reasoned that there must be some form of advertising to inform people about the procedure. Solomon Roth's comment "I should have gone home long ago" may be read to imply that suicide had already been suggested to him earlier, maybe at a certain age or with the decline of his working power.

The "priests" of this cult are employees dressed in long white gowns who act with great dignity and thereby create the impression of actual religious procedures taking place. They are the most important factor in making euthanasia appear as something religious and represent the facilities to the public. This lets me conclude that the creators of the cult - probably executives of the Soylent Corporation or of the government - seek to quench the religious thirst of people with these ceremonies. Since they are the representatives of this governmental institution for the public, it is reasonable to conclude that the society leaders in Soylent Green seek to quench the religious thirst of people with these ceremonies. Should there really be other motives besides economic interest for maintaining the facilities, this would point at a competition between the religions. However, I believe my earlier observation that the cult acts as a projection surface for individual religious feelings points away from a direct competition and towards a function as an outlet for spiritual wants. Instead of proposing a certain belief system of its own, the euthanasia cult lends itself to a diverse set of religious ideas. As the operators of the cult are the only authority with the power to grant people to "go home," they are in control of yet another instrument of power. Since their work directly assists the production of Soylent, we can assume they belong to the Soylent Corporation and receive payment and supplies from corporate funds. Nevertheless, they certainly do not know what becomes of the dead bodies. The Soylent facto- 
ries are heavily guarded and even the drivers of the garbage trucks are exchanged at the gates. Because, as Robert Thorn tells us, work on the so-called waste disposal plants is a sentence for life, no word of the conversion of corpses into food reaches the outside world.

Throughout the film, we see that power resides with those who have work and who can thus afford access to resources like room, food and other basic commodities. The poor are generally treated cruelly and contemptuously as illustrated by the practice of "scooping" them into trucks to end riots. Power is frequently accompanied by corruption and nepotism, for example in the police department or within the board of the Soylent Corporation.

The buildings that house the euthanasia cult are very modern, clean and spacious and are open to the public. In stark contrast to the general treatment of people by the government and the Soylent Corporation, officials here are very friendly and courteous. This certainly helps to attract new victims, but it also sheds light on a hypocritical and sinister attitude towards people. The sequence of scenes displaying Solomon's death in the euthanasia facility reveals how, instead of bringing salvation, the ceremony plays a fatal trick on the poor. Most obviously, the ceremonial rooms are called "theaters," indicating that the ritual is understood as an enactment. During the video show, the buoyant music takes away the gravity of the moment and the intense orange light lends Solomon a healthy complexion. However, before the last note has faded away, the lighting abruptly changes back to standard and an extreme close-up forces the viewer to look at Solomon's dead face in all its bluntness. This shows that the warmth and dignity of this scene is a masquerade disguising the cruelty of the procedure. As far as can be judged from the information given in the film, the euthanasia cult is very popular and attracts people from various religious backgrounds.

\section{The Depiction of the Christian Church}

As I have shown, the three groups in the religious world of Soylent Green have differing human and institutional representatives and unequal levels of popularity. The fictional euthanasia cult deserved special attention in the description above and, a corporate or governmental institution is assumedly the largest religious unit among the three. Nevertheless, I believe the Christian Church serves an even more complex function in the film's moral discourse. I will therefore proceed to further examine and interpret its depiction in the film, bearing in mind the context of a social, economic and moral crisis. My argument is that the Christian Church acts as the lone practitioner of long abandoned virtues such as altruism and magnanimity and provides helpful, if not vital services under the hostile circumstances. The evidence for this outstanding position among the institutions and characters can be grouped into three central functions fulfilled by church and clergymen: charitable actions, spiritual leadership and defense of morality. 


\section{Charity}

Given the city's massive overcrowding and lack of food supply, the necessity of help is obvious. This causes the church in Fleischer's Soylent Green to react in a very direct way. The church building itself becomes a refuge for masses of homeless, poor and sick people. In various scenes the viewer can observe the altruistic work of a number of nuns and the priest. They nurse the sick, set up and repair beds and continue to accommodate newly arrived people seeking help. At one point, Thorn finds an orphaned child and quite naturally takes it to the church for care. Apparently it is known to offer reliable support for those in danger.

A further characteristic of the church in this context is its lack of security devices and guards. The doors are unlocked, open to anyone wishing to enter, as there are no contracts to be negotiated and no payments to be made. This forms a sharp contrast to other scenes, in which we see for example the house entrance of Robert Thorn guarded by an armed watchman, who sends away people longing to sleep on the already crowded staircase. Such details underline the importance of charitable action and draw attention to the difference in attitude between the general public and the church. While accessibility is also a characteristic of the euthanasia facilities, these require an application and are of course interested in profiting from their clients rather than serving them. When Robert Thorn first visits the church to speak with the priest, he steps into a crowded, messy room with clouds of haze drifting through the air. By contrast, the euthanasia facilities are particularly spacious, clean and have a pleasant odor, which causes Solomon Roth to take a deep breath when stepping inside. All of this exemplifies that the material offers of the cult surpass those of the church by far. However, one must keep in mind that the church's offering is life sustaining while the cult's is life destroying.

Furthermore, the priest Paul is presented as a highly engagé, even altruistic laborer - working until mental and physical exhaustion. The knowledge of the true ingredients of Soylent Green, in his own words, "is killing" him and it truly does when Tab Fielding sneaks into the confessional to shoot him. This illustrates how the priest dedicates his work, health and his life to the cause of charity. The actions of both church and clergy appear as positive, commendable examples of reacting to the dramatic social circumstances. It must be acknowledged, however, that regardless of the considerable efforts described above, the church is not capable of vanquishing the social hardship of the Soylent Green society in its entirety. This is illustrated on a filmic level by the weariness of the priest, which intensifies to a near paralysis after he finds out the truth about Soylent Green. Also the small number of church workers in relation to the millions of homeless and unemployed people allows no other conclusion than a failure of the church to effect extensive change. But at the same time, the church's actions are singular in the world of Soylent Green. Nowhere else do the poor encounter genuine compassion, ingenuous amicability and unconditional readiness to help. As we can also see from the portrayal of Robert Thorn's investigations, the film is more interested in 
effort, commitment and perseverance than in the factual results of the struggle against injustice and immorality. Thus, the value of the church's actions and its moral integrity is not diminished by the irrefutable incapacity to overcome the unrighteousness present in the Soylent Green society.

\section{Spiritual Leadership}

But the agent of Christianity does not exhaust itself with practical help alone. The Roman Catholic Church in Soylent Green also takes the role of spiritual leadership for its members and guests, which is made most explicit by the administering of Catholic sacraments.

The sacrament of confession initiates the priest's involvement in Thorn's investigation and later provides the setting for his assassination. In this particular scene, long lines of people have formed in front of the confessional, showing that the act is nothing unusual and widely appreciated. The means of camera movements and shot selection employed in this sequence shed light on the effects of the difficult working conditions of the priest. Beginning with a panning medium shot that captures the amount of people waiting, the short scene continues with a shot inside the confessional. In contrast to the noise and the voices accompanying the first shot, the audio line to these pictures only contains Fielding's voice and the report of his gun. The camera is now absolutely stationary, conveying only Fielding's movement and the motionless priest in a close-up shot on eye-level. This selection of filmic devices emphasizes how the minister is almost paralyzed by his work, which he tries to pursue with great dedication. We must also take into account that confession is not simply a means of small talk or personal relief for the believer, but a religious necessity for absolution. Since the priest is the only one able to accept a confession, his role as a spiritual leader is eminent even in spite of the unsoundness of his mental and physical health.

For that matter, the priest himself is evidence of another sacrament, namely the ordination. This special kind of blessing is endowed by the spiritual authority of the church and enables him to effectively administer sacraments. His presence therefore hints at a higher, functioning ecclesiastic authority.

A sacrament that is not directly present in the film is communion. There is no celebration of communion and none of the characters mention it directly. It is reasonable to believe that communion cannot take place in the world of Soylent Green, because of the horrendous price of bread and wine. But perhaps featuring communion in this film was avoided purposefully since it might mock Christian beliefs and thus compromise the generally positive depiction of Christianity. In a world in which people eat food made from the dead everyday, the somewhat similar procedure of communion would be hardly bearable. As if to close this gap in the set of religious rituals, the euthanasia procedure involves a perverted version of communion. The priest-like executioners hand the poison to the Jew Solomon 
Roth in a large goblet, much like the ones used in Mass. It remains unclear whether the theological implications of this are meant to suggest a conflict between Judaism and Christianity, or whether they are just a side effect of the imitative elements in the cult.

\section{Stronghold of Morality}

In view of the dysfunctional society of Soylent Green and in opposition to the barbaric business scheme of the corporation, the church becomes a veritable stronghold of morality. I have chosen this admittedly strong expression, because the idea of defense and safekeeping inherent in the word "stronghold" is similar to the institution's function in the film. The priest and his affiliates do not attack or openly confront the moral failures surrounding them, but rather act as a refuge to those in difficulties and provide a moral safe-haven.

Most tellingly, the church is repeatedly presented as a trustworthy place where moral issues are concerned. Soylent manager Simonson, seeking to relieve himself of his knowledge about the food substitute and to come to terms with his immoral deeds in the past, turns to the church. In his desperation for moral righteousness, this is the place where he wants to go to even at the cost of his life. In the eyes of this defector, the church is the institution that is the farthest away from the debauched corporation. At the same time, it is open and accessible.

Another detail supporting the claim that the church is a stronghold is the use of the church building as the setting for the final battle between Thorn and Fielding. After the wounded Thorn has escaped from the Soylent factory into the church, the crowd within gives him coverage and he is finally able to decide the fight in his favor. As it is a battle between truth and lie, between morality and immorality, this choice of location is significant. It indicates that the building is home ground to the hero and a helpful ally against his opponents. Again, the church has a considerable impact on the course of events. While it remains unclear whether Thorn's investigations are going to provoke profound changes, he has done everything in his power to contribute to a good cause. This is exactly what the priest and the church are doing as well and it shows an attitude of persistent courage, which is most benevolently portrayed by the makers of Soylent Green.

\section{Criticism}

Following the presentation of my paper in the seminar and at the undergraduate conference in June and July of 2009, fellow students stated some criticism. It mainly concerned the question of whether or not to consider the activities of the priest and the church as lasting accomplishments and thus arrive at a positive reading of their depiction - as this chapter claims. Arguments brought up against 
this reading are the limited effects on society in general, and an understanding of the priest's exhaustion as incompetence. I appreciate these remarks and recognize that they do form a legitimate interpretation. Yet the outstanding position of the Christian Church and its representatives in the context of multiple crises is so strongly emphasized that it is able to refute the counter-arguments. The depiction of the priest, the church and even Robert Thorn is based on a simple and plausible conclusion: The scale of the challenge does not compromise the value of moral behavior and altruistic help.

\section{Conclusion}

In view of the scarce amount of works published on the film Soylent Green, every paper on this film requires some initiative to begin and investigate a certain topic. In this case, the opening observation was the frequent appearance of religious elements throughout the film. Analyzing and describing the instances of Judaism, Christianity and a fictional euthanasia cult in the story, my attention then turned towards the depiction of the Christian Church. There, I paid special attention to the critical circumstances of social, economic and moral downfall under which it makes its efforts. The thesis tested here stated that it occupies leading positions on the fields of charity, spirituality and morality. Various instances of such depiction found on the levels of plot and scenic realization supported this reading, for example, the reliance of multiple characters on the church in moral issues or the choice of the church building for the final battle. The sum of these arguments outweighs remarks that are critical of such a reading of the film and opens up new questions concerning the relations between the different religious groups. With my argumentation, I hope to have shown the relevance of religious institutions for the film and to have sharpened the perception of the moral and religious discourse. 


\section{Works Cited}

Bereton, Pat. Hollywood Utopia: Ecology in Contemporary American Cinema. Bristol: Intellect, 2005. Print.

Evangelische Kirche in Deutschland, ed. Die Bibel: Nach der Übersetzung Martin Luthers. Stuttgart: Deutsche Bibelgesellschaft, 2001. Print.

Harrison, Harry. Make Room! Make Room! 1966. New York: Tom Doherty Associates, 2008. Print.

Lipschutz, Ronnie D. “'Soylent Green ... is ... PEOPLE!': Labour, Bodies and Capital in the Global Political Economy." Millenium 34 (2005). 573-76. Print.

Sobchack, Vivian. Screening Space: The American Science Fiction Film. New Brunswick, NY/London: Rutgers UP, 1999. Print.

Soylent Green. Dir. Richard Fleischer. Perf. Charlton Heston, Leigh Taylor-Young, and Edward G. Robinson. 1973. MGM, 2003. DVD. 